\title{
Stock assessment of Japanese eels using Japanese abundance indices
}

\author{
Eiji Tanaka
}

Received: 6 February 2014 / Accepted: 2 August 2014/Published online: 19 September 2014

(C) The Author(s) 2014. This article is published with open access at Springerlink.com

\begin{abstract}
The paper compiles a catch history of Japanese eels Anguilla japonica in East Asia and some Japanese relative abundance series. Maximum likelihood estimates of stock abundance of eels have been obtained using the abundance series and various biological parameters, such as growth, maturity and natural mortality. Age- and sexstructured models have been used to express the dynamics of stock abundance, and the Beverton and Holt model has been used to express the relationship between stock and recruitment. Data for estimations are standardized catch per unit effort of commercial fishery for exploitable stock (1954-2006 and 1968-2008) and for glass eel (1954-2010, 1972-2004, and 1973-1997). From the results of the base case scenario of estimations, the estimated stock size of individuals aged $\geq 1$ year was 18.7 thousand tons in 2010 , which was $24 \%$ of the carrying capacity. The estimated stock size has recovered since 1990. Maximum sustainable yield was 4,180 tons if only the exploitable stock were utilized, and 266 tons if only the glass eel were utilized. These results and issues relating to estimation and management for reducing the fishery impact on stock are discussed.
\end{abstract}

Keywords Japanese eel - Maximum likelihood · Parameter estimation · Stock assessment

Electronic supplementary material The online version of this article (doi:10.1007/s12562-014-0807-x) contains supplementary material, which is available to authorized users.

E. Tanaka $(\square)$

Tokyo University of Marine Science and Technology,

Konan 4-5-7, Minato, Tokyo 108-8477, Japan

e-mail: hermit@kaiyodai.ac.jp

\section{Introduction}

Sustainable stock of Japanese eel Anguilla japonica is important to freshwater fisheries in Japan where the eel stock is primarily exploited for two objectives: human consumption and seeds for aquaculture. Traditional fisheries, such as pod, long-line and set net, exploit fishery stock consisting of yellow-stage and silver-stage eels [1] of commercial size (referred to as "exploitable stock" in the following text) for human consumption. Juveniles (eels smaller than the commercial size) can be harvested by some fisheries either incidentally on a case-by-case basis or under special permit for seeds. Japanese eel fisheries have a long history, going back many hundreds of years. Smallscale fisheries, such as hand-net and bag net, are only allowed to exploit glass eel stock for aquaculture seed under prefectural special permit, in association with aquaculture.

Japanese eel aquaculture began in 1879 [2], at which time all seeds were natural juveniles caught by the traditional fisheries. Commercial utilization of glass eels for seed first succeeded in 1923, followed by the rapid development of aquaculture systems using glass eels in the 1930s [3, 4], as well as takes of glass eels. The takes dropped in World War II, but by 1957 had recovered to the level before World War II [5]. Eel aquaculture utilizing glass eels rapidly developed in the 1970s-1980s in China, Korea and Taiwan [6, 7]. Currently, glass eels for seed are taken from the coastal zones of all countries and regions and are traded internationally.

According to official Japanese statistics (http://www. maff.go.jp/j/tokei/kouhyou/naisui_gyosei/index.html), the average catch of exploitable stock [300 tons (rounded off)] during the period 2006-2010 was greater than that of glass eels (12 tons) and much smaller than that from aquaculture 
(21,000 tons). Therefore, aquaculture production is economically relatively more important than fisheries in terms of exploitable stock. According the statistics of the Food and Agriculture Organization of the United Nations (FAO; http://www.fao.org/fishery/statistics/software/fishstat/en), other countries and regions mainly exploit glass eels for seeds in aquaculture while Japanese fisheries share the majority of exploitable stock catch because the consumption of eels as food in countries other than Japan is local.

The catch of exploitable stock and glass eel in Japan has been steadily decreasing in recent years, with the latest estimates of the average catch of exploitable stock at approximately $8 \%$ of the maximum post-World War II. Depletion of stock is a matter of grave concern, and three reasons have been suggested to account for the reduced catch [8]: overexploitation of stock, (commercial/industrial) development of rivers and changes in the ocean environment. Although the reduction in stock size can be accurately assessed, there is much uncertainty about the level of depletion since it is estimated based on the catch amount.

Another reason for the decreasing catch amount is associated with the drastic decline in freshwater fisheries in Japan [9]. Both the fishery census in 1968 [10] and successive censuses have revealed that the total amount of fishing units in major Japanese lakes (except for gillnet, throw net, shellfish and seaweed fisheries) have decreased from 4,082 units in 1968 to 977 in 2008 and that the units targeting exploitable stock of eels have decreased from 551 units in 1968 to 91 in 2008 (Fig. 1). In Lakes Kasumigaura and Kitaura, where the eel catch in 1963 was $11 \%$ of the total catch in Japan, the fishing effort has decreased from 588 (1,000 day-boats) in 1963 to 44.1 in 2001 (Fig. 2; see annual statistics in 1954 [11] and successive volumes for sources). Thus, the decline in fisheries had a serious impact on productivity. Therefore, conducting some stock assessment is necessary to reliably estimate the level of depletion.

Stock assessments have been carried out for the European eel Anguilla anguilla and the American eel Anguilla rostrata $[12,13]$ using current statistical methods, such as stock synthesis [14]. Age- and sex- (or length-) structured models were used in the latter assessment as dynamical models of stock size $[15,16]$, and the effect of natural mortality after spawning was incorporated into the models to express the more realistic dynamics of eel stock size. Stock assessment of the Japanese eel needs data such as catch statistics, abundance index, CPUE (catch per unit effort) and biological and operational parameters (including age and growth, natural mortality, sexual maturity and gear selectivity).

Studies on the biological aspects essential for a stock assessment of Japanese eel have produced an abundance of

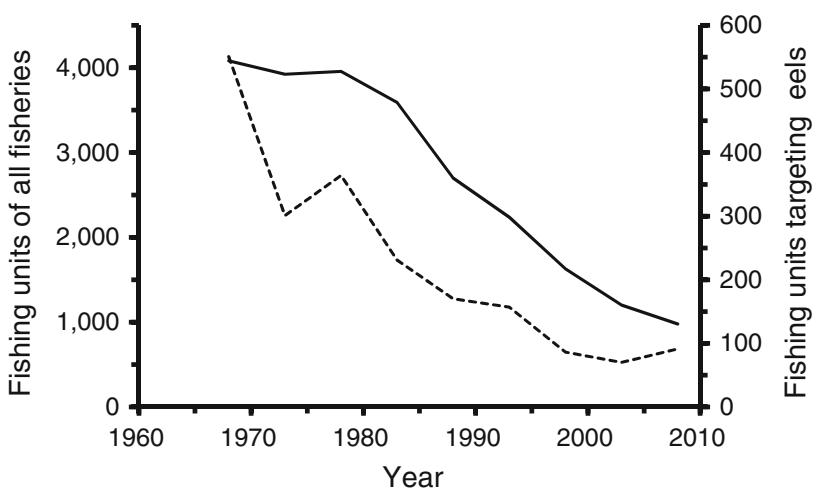

Fig. 1 Changes in number of economic fishing units in Japanese major lakes. Solid curve Number of the units of all fisheries, with the exception of gillnet, throw net, shellfish and seaweed, dotted curve number of fisheries targeting exploitable stock of eels

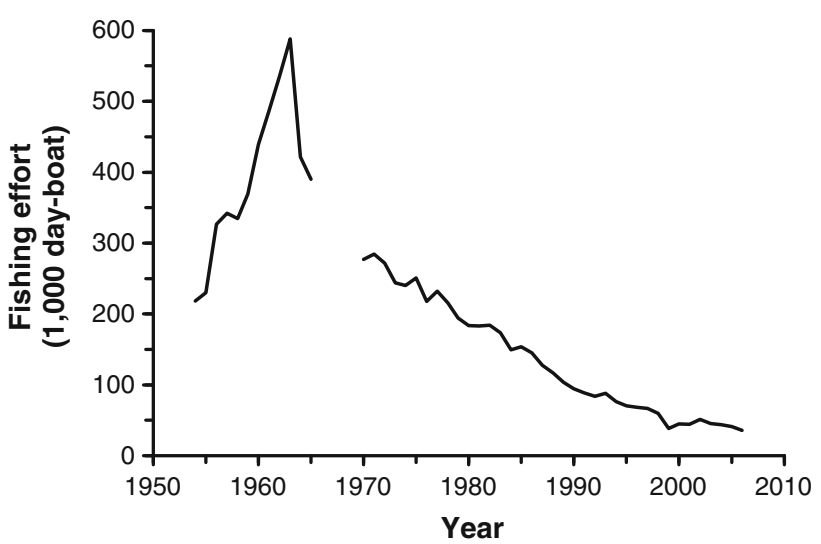

Fig. 2 Changes in fishing effort over time in Lakes Kasumigaura and Kitaura

data $[1,17-21]$. Previous research shows that there is no genetic difference between the eel stocks in Japanese and Chinese waters and that eels born in early summer arrive at the continental areas during the following winter as glass eels. Sex differences in the weight growth equation have been estimated in various areas in addition to the age at sexual maturity. The biggest difficulty in stock assessment of the Japanese eel is the lack of systematic data on both catch records and the index of stock abundance. Moreover, it is necessary to gather various data in the form of scientific and industrial reports and systematically compile these for stock assessment.

In this report I have compiled the catch history of Japanese eels and standardized the CPUE for exploitable and glass eel stocks from published and unpublished data in scientific and industrial reports. I have also determined the MLE (maximum likelihood estimate) of historical changes in eel stock size using these compiled data, based on biological parameters. The dynamical model used for this estimation is a variant of sex- and age-structured 
Table 1 Data sources for compilation of catch statistics

\begin{tabular}{|c|c|c|c|c|}
\hline $\begin{array}{l}\text { Stock } \\
\text { component }\end{array}$ & $\begin{array}{l}\text { Countries and } \\
\text { region }\end{array}$ & Data & Period & Sources \\
\hline \multirow{7}{*}{$\begin{array}{l}\text { Exploitable } \\
\text { stock }\end{array}$} & East Asia & Catch & 1958-2010 & FAO statistics ${ }^{\mathrm{a}, \mathrm{b}}$ \\
\hline & Japan & Catch $^{\mathrm{a}}$ & 1903-1911 & Annual statistics ${ }^{c}[24]$ \\
\hline & & & $1912-1943$ & Statistics over the years [25] \\
\hline & & & $1950-1953$ & Statistics over the years [25] \\
\hline & & & 1954-2010 & Annual statistics ${ }^{c}[11]$ \\
\hline & China & Exports into Japan & 1973-1992 & Foreign trade statistics [6] \\
\hline & Taiwan & Aquaculture & $1958-1980$ & Taiwanese statistics [7] \\
\hline \multirow[t]{7}{*}{ Glass eels } & China & Stocked glass eels & 1990-2010 & Newspaper ${ }^{\mathrm{d}}$ \\
\hline & Korea & Stocked glass eels & $1972-2010$ & Newspaper $^{\mathrm{d}}$ \\
\hline & Japan & Stocked glass eels & 1972-2010 & Newspaper $^{\mathrm{d}}$ \\
\hline & & Takes & $1957-2010$ & Annual statistics ${ }^{c}[11]$ \\
\hline & & Aquaculture production & $1929-1963$ & Statistics over the years [25] \\
\hline & Malaysia & Stocked glass eels & 1991-1996 & Newspaper ${ }^{\mathrm{d}}$ \\
\hline & Taiwan & Stocked glass eels & 1980-2010 & Newspaper $^{\mathrm{d}}$ \\
\hline
\end{tabular}

${ }^{\text {a }}$ Including Japanese takes of glass eels

b See Food and Agriculture Organization of the United Nations (FAO) web page for sources

c Only first volume of statistical series was cited

d Japan Aquaculture

Newspaper, unpublished, 2013 data have been published in part in industrial journals (e.g. Anonymous [34]).

Japanese statistics and census data were used for two series of abundance indices of exploitable stock, and meeting reports and research reports included three series of abundance index of glass eels.

\section{Compilation of catch history for exploitable stock}

In the Japanese statistics, catch records missing for the period 1944-1949 were linearly interpolated because catch in the major lakes, Lake Kasumigaura and Kitaura, did not collapse during the period encompassing World War II [35]. Data from the shrunk scale of the survey since 2001 were corrected by a calibration factor, converting the catch in the shrunk scale of the survey to that of the full scale. The calibration factor was calculated using data in the year when both surveys were carried out. For the 1958-2010 catch in East Asia, FAO statistics were used. The catch for 1903-1957 was obtained by multiplying the Japanese catch by the rate of total catch in East Asia to that in Japan [the rate $=1.11$, $95 \%$ confidence limit (CL) 1.03-1.18]. The rate was calculated using the sum of the annual catch from 1958 to 2010 . The annual rate ranged from 1.00 to 1.55 and seemed to be periodical, with peaks occurring around 1981 and 2009.

Compilation of catch history for glass eels

In this study, total takes of glass eels in East Asia were obtained from the sum of the amounts of stocked glass eels. Records on takes of glass eels in all the countries and regions are lacking for the initial stage of aquaculture development (Table 1). In Japan, records of takes between 1930 and 1956 are lacking despite substantial takes of glass 
Table 2 Japanese data sources for series of index of stock abundance a Only first volumes of statistical series was cited

b Prefectural editions of annual statistics for details on numbers c 5-year interval

\begin{tabular}{|c|c|c|c|c|}
\hline $\begin{array}{l}\text { Stock } \\
\text { component }\end{array}$ & Areas & Data & Period & Sources \\
\hline \multirow[t]{4}{*}{$\begin{array}{l}\text { Exploitable } \\
\text { stock }\end{array}$} & \multirow[t]{2}{*}{$\begin{array}{l}\text { Lakes Kasumigaura and } \\
\text { Kiataura }\end{array}$} & Catch and effort & 1954-2006 & $\begin{array}{l}\text { Annual statistics }{ }^{\mathrm{a}} \\
\text { [11] }\end{array}$ \\
\hline & & Catch and effort & 1954-1969 & $\begin{array}{l}\text { Annual statistics }{ }^{\mathrm{a}, \mathrm{b}} \\
\text { [26] }\end{array}$ \\
\hline & \multirow[t]{2}{*}{$\begin{array}{l}\text { Twelve lakes in major } \\
\text { lakes }\end{array}$} & \multirow[t]{2}{*}{ Catch effort } & 1968-2008 & $\begin{array}{l}\text { Annual statistics }{ }^{\mathrm{a}} \\
\text { [11] }\end{array}$ \\
\hline & & & 1968-2008 & Census $^{\mathrm{a}, \mathrm{c}}[10]$ \\
\hline \multirow[t]{4}{*}{ Glass eels } & Nine prefectures & $\begin{array}{l}\text { Monthly catch and } \\
\text { effort }\end{array}$ & 1977-1997 & Meeting report ${ }^{\mathrm{a}}[27]$ \\
\hline & \multirow[t]{2}{*}{ Lake Hamana } & \multirow[t]{2}{*}{ Abundance catch } & 1972, 1974-2006 & $\begin{array}{l}\text { Research report } \\
\text { [29] }\end{array}$ \\
\hline & & & 1954-2010 & $\begin{array}{l}\text { Research report }[5, \\
27-32]\end{array}$ \\
\hline & Tokushima Prefecture & $\begin{array}{l}\text { Seasonal } \\
\text { abundance }\end{array}$ & $\begin{array}{l}\text { 1973-1974, } \\
1976-1977\end{array}$ & Research report [33] \\
\hline
\end{tabular}

eels being started in 1930. For the period 1944-1956, I estimated Japanese takes of glass eels by dividing the annual aquaculture production by the rate $(36.6,95 \% \mathrm{CL}$ 29.5-43.6) of the production averaged over period 1957-1963 to the averaged takes of glass eels in Japanese statistics. For the period 1930-1943, the seeds of two kinds were used, and takes of glass eels were calculated by dividing the increases in annual production in each year from that in 1929 with the rate. For the 1957-1971 records of takes of glass eels, catch statistics were used because (1) Korea and Taiwan prohibited the export of glass eels and the imported amounts from China was negligible and (2) no exports of live fish to those countries was recorded in the foreign trade statistics of Japan. For 1972-2010, two estimates (takes and seeds) were available and the greater of the two estimates was adopted for the total takes of glass eels because Japan has officially prohibited exports of eels weighing $<13$ g since 1976.

Substantial commercial aquaculture using glass eels began in 1957 in Taiwan, 1973 in China and 1965 in Korea $[6,7]$. Taiwanese takes of glass eels (1957-1979) and Chinese takes of glass eels (1973-1989) were estimated by dividing aquaculture production by the rate of stocked glass eels to the production. The rate was calculated with data for 1980-1985 for Taiwanese takes and in 1990-1992 for Chinese takes. The amount of imported eels into Japan from China [6] was regarded as the Chinese aquaculture production because records of the production in FAO statistics were too large compared with the amount of stocked glass eels. The amount of stocked glass eels in Korea (1965-1971) was extrapolated assuming a linear increase. Eel aquaculture in Malaysia seemed to be temporal, and no exploration was made, but interpolation for lacking data was applied as a general rule. The catch history is illustrated in Fig. 3.
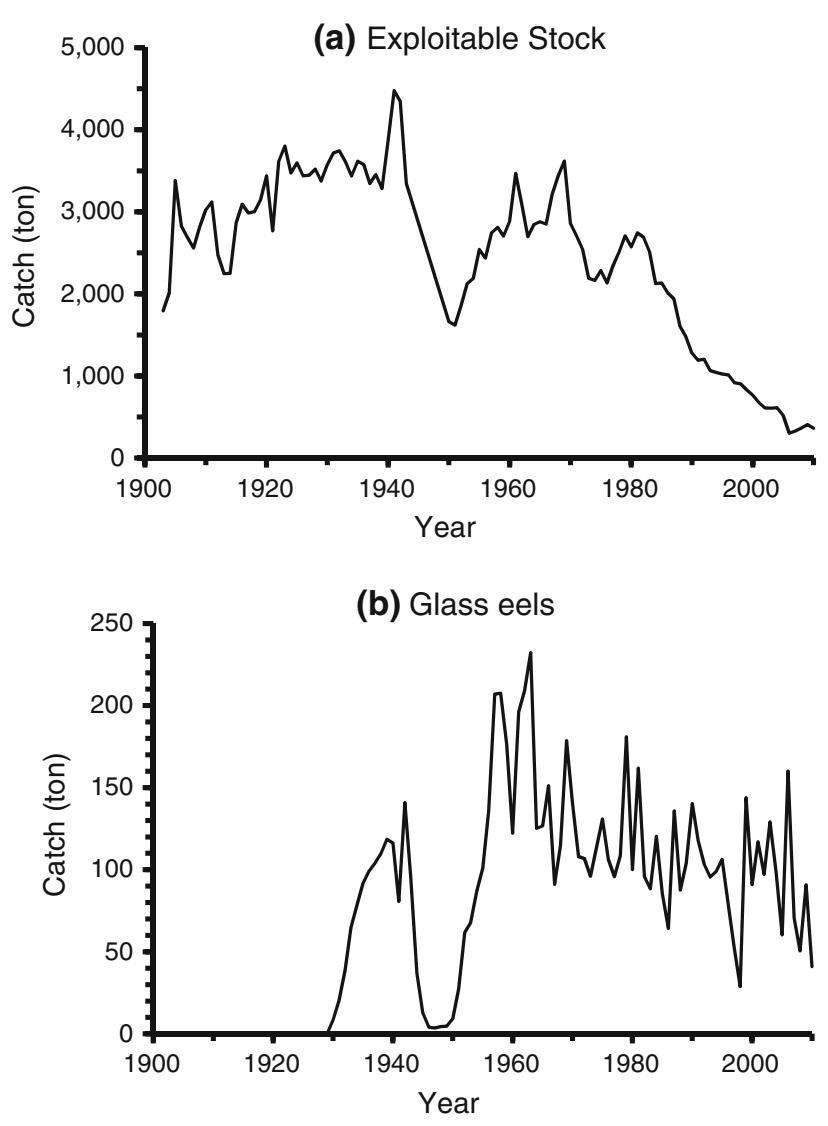

Fig. 3 Compiled catch history for Japanese eel in East Asia

Standardization of CPUE of commercial fisheries for exploitable stock

Before the stock assessment was performed, noise in the raw data of CPUE was removed. Two CPUE series for exploitable stock and two CPUE series for glass eel are 
used in this study. To distinguish the stock components, the code of the stock components is denoted by $z(z=0$ for glass eels, $z=1$ for exploitable stock and $z=2$ for stock aged one and older), and data sources are indicated by $i\left(=1,2, \ldots, I_{\mathrm{MAX}, z}\right)$. Let $u_{z, i, t, k}$ be CPUE (kg/day-boat) of fishery $i$ in year $t(=1954, \ldots, 2006)$ for area $k\left(=1,2, \ldots, K_{\mathrm{MAX}, z, i}\right)$.

Expectations of the natural logarithm of standardized CPUE from commercial fisheries for exploitable stock and their variance for 1954-2006 in Lake Kasumigaura and Kitaura were estimated using annual catch (tons) and effort (day-boat) obtained from the annual statistics [11, 26]. Note that the definition of unit of effort has changed since 2002, and the factor to convert the new unit to the older one is unknown. Since the sum of effort (day-boat) in the two lakes is only known for the period 1960-1968, the sum of effort was divided over the two lakes using the proportion of provisional effort (dayboat) in each lake. This was estimated using the number of fishing units in each lake and average operation days per fishing unit for 1969-1972 in each lake. In order to remove the main effects of lake and randomness, CPUE is assumed to be expressed by the following log-normal distribution:

$$
\begin{aligned}
& \ln \left(u_{1,1, t, k}\right)=\ln \left(u_{1,1, t, *}\right)+\alpha_{1,1, k}+\varepsilon_{1,1, t, k} \\
& \quad(k=1 \text { for Kasumigaura, } 2 \text { for Kitaura }) .
\end{aligned}
$$

Here $u_{1,1, t, *}, \alpha_{1,1, k}\left(\alpha_{1,1,1}=0\right)$ and $\varepsilon_{1,1, t, k}$ are year effects, lake effect and error, respectively. The moment estimates were used since the number of lakes was only two. From the results of the estimation, the value of $\hat{\alpha}_{1,1,2}$ was 0.17 [standard error $(\mathrm{SE})=0.077$ ]. The expectation of standardized CPUE of commercial fisheries in the lakes, used for stock assessment, was expressed by

$\mathrm{E}\left[u_{1,1, t, *}\right]=\exp \left\{\ln \left(\hat{u}_{1,1, t, *}\right)+\frac{\hat{\mathrm{V}}\left[\ln \left(u_{1,1, t, k}\right)\right]}{2}\right\}$.

For the second CPUE series (1978-2008), based on catch in the annual statistics [11] and effort in the fisheries census [10], the same model as Eq. 1 was used as the statistical model of the CPUE $\left(u_{1,2, t, k}\right)$. The census, conducted at 5 -year intervals, surveyed the number of economic fishing units in important lakes. In total, 12 lakes were selected (Ogawarako, Kasumigaura, Kitaura, Hinuma, Inbanuma, Teganuma, Mikatagoko, Kitagatako, Koyama-ike, Togoko, Shinjiko and Jinzaiko). These lakes are associated with the migratory corridor of eels, and both the number of fishing units and catch statistics were available. The maximum likelihood method was used for parameter estimation. Values of $\hat{\alpha}_{1,2, k}$ ranged from -2.37 (SE 0.454) to 0.246 (SE 0.284).
Standardized CPUE of commercial glass eel fisheries

The standardized logarithm of commercial CPUE ( $\mathrm{kg} /$ fisher) for glass eels from 1977 to 1997 was estimated by the maximum likelihood method using data of catch and effort from nine prefectures. The data were obtained from each annual meeting report [27], up until the last one [28]. In this study, the annual take of glass eels is taken as the sum of takes from November of the previous year to April in the year of interest. Observation of the logarithm of CPUE is assumed to be expressed by the following log-normal distribution:

$\ln \left(u_{0,1, t, k}\right)=\ln \left(u_{0,1, t, *}\right)+\alpha_{0,1, k}+\varepsilon_{0,1, t, k}$.

Here $\alpha_{0,1, k}$ is prefecture effect. The values of $\hat{\alpha}_{0,1, k}$ were -1.15 (SE 0.16) (Shizuoka Prefecture), 0 (Chiba as standard), -0.85 (SE 0.17) (Aichi), -2.01 (SE 0.14) (Mie), -1.17 (SE 0.15) (Tokushima), -1.38 (SE 0.13) (Kochi), -1.19 (SE 0.11) (Oita), -0.93 (Se 0.19) (Miyazaki) and -1.38 (SE 0.11) (Kagoshima).

Since the CPUE series of glass eel fisheries are not available for 1954-1976 and 1998-2010, respectively, the CPUE for these years was inferred using catch records of glass eels in Lake Hamana for 1954-2010. [5, 27-32]. I used these records because (1) although a gradual decrease in the number of fishers probably occurred over the years, a minimum 300 fishers on the lake is sufficent to root out glass eels in the lake and the records are expected to reflect the amount of glass eels that migrated into the lake, and (2) the annual amount of takes in Lake Hamana correlated with the Japanese total ( $r=0.77$, in log-scale for 1957-2010). In order to estimate the CPUE (kg per unit effort), the following log-linear model is used:

$$
\begin{aligned}
\ln \left(\mathrm{E}\left[u_{0,1, t, *}\right]\right)= & \gamma_{0}+\gamma_{1} \ln \left(y_{t}\right) \\
& +\varepsilon_{0, t}^{\prime} \quad(t=1976, \ldots, 1996) .
\end{aligned}
$$

Here $y_{t}$ and $\gamma_{b}(b=1,2)$ are the amount of takes in Lake Hamana and the regression coefficient, respectively. The expected value of $\hat{\gamma}_{0}+\hat{\gamma}_{1} \ln \left(y_{t}\right)+\varepsilon_{0, t}^{\prime}$ for $1954-1976$ and 1998-2010 and its variance are used for the stock assessment. The values of $\hat{\gamma}_{0}$ and $\hat{\gamma}_{1}$ were 2.81 (SE 0.51) and $0.476(\mathrm{SE} 0.025)(r=0.75)$, respectively.

Standardization of abundance index from research survey for glass eels

In Lake Hamana, the abundance survey using a set net [29, 30] was carried out in November during the period 1972-2004 at two sites in the lake. The annual survey frequency ranged from 1 to 7 times per year (average 3.9 times per year), and the number of glass eels taken during each survey was counted. Although the survey data failed to predict the total amount of the takes during the successive fishing season, the data 
collected over 30 years were sufficient for effectively estimating long-term changes in abundance.

Along the coast of Tokushima Prefecture, surveys using hand-nets were simultaneously carried out in 1973-1974 and 1976-1977 [33] at various sites and during different months. CPUE records according to day and region (north or middle) were reported, and data from December to April in the subsequent year were used for estimating the parameters.

Let $c_{i, t, m, k, j}$ be CPUE (eel/operation) of the $j\left(=1,2, \ldots, J_{\mathrm{MAX}, z, i}\right)$ th operation of survey $i(=2,3)$ in month $m\left(=1,2, \ldots, m_{\mathrm{MAX}}\right)$ of year $t(=1972, \ldots, 2002$, or $1973, \ldots, 1977))$ for site $k\left(=1,2, \ldots, K_{\mathrm{MAX}, z, i}\right)$. In the abundance survey of glass eels, the frequency of zero CPUE was so high that zero-inflated models, such as those used in the analysis of data from tuna longline fishery [37, 38], were applied. The CPUE (fish/operation) is expressed by the following zero-inflated negative binomial distribution:
Basic dynamical models

The following assumptions have been made: (1) stock of Japanese eels is single; (2) all mature eels die after spawning; (3) natural mortality, body growth and agespecific rate of recruitment are constant over all years; (4) the age of glass eel in the Japanese continental shelf is considered to be 0.5 years from birth for mathematical convenience; (5) the fishing season is short and the catch is concentrated on the birth day.

The basic dynamical models are similar to the sex- and agestructured models used to assess European [12] and American eels [13], and the number of recruits (glass eels) is expressed by the Beverton and Holt model [14-16, 22]. The majority of equations in the models for eel stock are common to those used for other fishery stocks. The unusual characteristic of the dynamical models of eel stock assessment is the incorporation of extra-mortality due to sexual maturity and spawning.

$P\left(c_{i, t, m, k, j}\right)= \begin{cases}1-\delta_{i, t} & \left(c_{i, t, m, k, j}=0\right) \\ \delta_{i, t} \frac{\Gamma\left(\chi_{i}+c_{i, t, m, k, j}-1\right)}{\Gamma\left(\chi_{i}\right)\left(c_{i, t, m, k, j}-1\right) !}\left(\frac{\chi_{i}}{v_{i, t, m}+\chi_{i}-1}\right)^{\chi_{i}}\left(\frac{v_{i, t, m}-1}{v_{i, t, m}+\chi_{i}-1}\right)^{c_{i, t, m, k}-1} & \left(c_{i, t, m, k, j}=1,2, \ldots\right) .\end{cases}$

Here $\delta_{i, t}, v_{i, t, m}$ and $\chi_{i}$ are the probability of nonzero CPUE, the conditional mean and shape parameter, respectively. Statistical models of the conditional mean and model of probability of zero CPUE are expressed by

$v_{i, t, m}= \begin{cases}1+\exp \left(\beta_{2, t}+\varsigma_{2, k}\right) & (i=2 \text { for Lake Hamana }) \\ 1+\exp \left(\beta_{3, t}+\xi_{3, m}+\varsigma_{3, k}\right) & (i=3 \text { for Tokushima })\end{cases}$

$\delta_{i, t}=\exp \left(-\kappa_{0, i}-\kappa_{1, i} t\right), \quad\left(\kappa_{0, i}, \kappa_{1, i}>0\right)$.

Here $\beta_{i, t}, \xi_{i, m}$ and $\varsigma_{i, k}$ are year, month and site effects, respectively, and $\kappa_{0, i}$ and $\kappa_{1, i}$ are coefficients.

Parameters were estimated by the MLE method, and the best model was statistically selected using the Akaike information criterion from several models, such as $\varsigma_{i, k}=0$ and/or $\kappa_{1, i}=0$. The selected model was expressed by $v_{2, t, m}=1+\exp \left(\hat{\beta}_{2, t}\right)$ and $\delta_{2, t}=\exp \left(-\hat{\kappa}_{0,2}-\hat{\kappa}_{1,2} t\right)$ for

Lake Hamana, and by $v_{3, t, m}=1+\exp \left(\hat{\beta}_{3, t}+\hat{\xi}_{3, m}\right)$ and $\delta_{i, t}=1$ for Lake Tokushima.

For each survey, expectation of CPUE using only the year effect was used for stock assessment and is expressed by

$\mathrm{E}\left[u_{0, i, t, *}\right]=\hat{\delta}_{i, t}\left\{1+\exp \left(\hat{\beta}_{i, t}\right)\right\} \quad(i=2,3)$.
Notations used in the article are listed in Table 3, and their meanings are similar to those used in other dynamical models [16, 22, 23] with two exceptions made for mathematical convenience: (1) age at recruitment is 0.5 years but in the suffix, $a=0$ was used; (2) the unit of mortality coefficient at suffix $a=0$ is half a year. The models are expressed by

$N_{s, a, t}=\left\{\begin{array}{lll}\frac{1}{2} R_{t} & (a=0) & (9 \mathrm{a}) \\ N_{s, a-1, t-1} \exp \left(-M_{a-1, t-1}-F_{s, a-1, t-1}\right)\left(1-m_{s, a-1}\right) & \left(a=1, \ldots, a_{\mathrm{MAX}}\right), & (9 \mathrm{~b})\end{array}\right.$

$P_{z, t}= \begin{cases}w_{0} R_{t} & (z=0) \\ \sum_{s} \sum_{a=1}^{a_{\mathrm{MAX}}} S_{s, a} w_{s, a} N_{s, a, t} & (z=1) \\ \sum_{s} \sum_{a=1}^{a_{\mathrm{MAX}}} w_{s, a} N_{s, a, t} & (z=2),\end{cases}$

$Y_{z, t}=E_{z, t} P_{z, t}$,

$E_{z, t}=1-\exp \left(-f_{z, t}\right)$,

$F_{s, a, t}= \begin{cases}f_{0, t} & (a=0) \\ -\ln \left\{1-S_{s, a}\left(1-\exp \left(-f_{1, t}\right)\right)\right\} & \left(a=1, \ldots, a_{\mathrm{MAX}}\right),\end{cases}$

$M_{a, t}= \begin{cases}M_{0} d_{M}(t) & (a=0) \\ M_{a} & (1 \leq a),\end{cases}$ 
Table 3 Parameters, data and variables for Japanese eel assessment model

\begin{tabular}{|c|c|}
\hline Variable & Description \\
\hline$a$ & Age in years $\left(a=0,1,2, \ldots, a_{\mathrm{MAX}}\right)$ \\
\hline$a_{0, s}$ & Age at length zero (year) \\
\hline$a_{m, s}$ & Age at $50 \%$ maturity (year) \\
\hline$a_{S, s}$ & Age at $50 \%$ recruitment (year) \\
\hline$b_{w}$ & Power coefficient of von Bertalanffy growth equation \\
\hline$B_{\mathrm{MAX}}$ & Mature female biomass at saturation level (ton) \\
\hline$B_{t}$ & Mature female biomass (ton) \\
\hline$c_{i, t, m, k}$ & $\begin{array}{l}\text { Number of glass eels caught by survey (fish/ } \\
\text { operation) }\end{array}$ \\
\hline$E_{z, t}$ & Annual exploitation rate \\
\hline $\begin{array}{l}d_{M}(t), d_{R}(t) \\
\quad d_{u}(t)\end{array}$ & Correction factor of $M_{0}$ or $R_{\mathrm{MAX}}$ or $u_{1, i, t, k}$ \\
\hline$f_{z, t}$ & Fishing coefficient (per year) \\
\hline$F_{s, a, t}$ & Fishing coefficient by age and sex (per year) \\
\hline$g\left(B_{t}\right)$ & Recruitment function of $B_{t}$ \\
\hline$h$ & $\begin{array}{l}\text { Steepness }(0.2<h<1 \text {, shape parameter in Beverton } \\
\text { and Holt model of stock and recruitment })\end{array}$ \\
\hline$i$ & Code number of fishery $\left(i=1,2, \ldots, I_{\mathrm{MAX}, z}\right)$ \\
\hline$j$ & Counter of number of data \\
\hline$k$ & Area or site $\left(k=1,, 2, \ldots, K_{\mathrm{MAX}, z, i}\right)$ \\
\hline$K_{s}$ & $\begin{array}{l}\text { Growth coefficient of von Bertalanffy growth } \\
\text { equation (per year) }\end{array}$ \\
\hline$l_{n}$ & $n(=1,2, \ldots)$ th likelihood \\
\hline$m$ & Month \\
\hline$m_{s, a}$ & Maturity rate \\
\hline$M_{a}$ & Natural mortality coefficient (per unit time) \\
\hline$N_{s, a, t}$ & Stock size in number \\
\hline$p_{M}, p_{R}, p_{u}$ & Rate of new saturation level to initial level \\
\hline$P_{z, t}$ & Stock size (ton) \\
\hline$q_{z, i, t}$ & Catchability coefficient of series $j$ for stage $z$ \\
\hline$r_{m, s}, r_{S, s}$ & $\begin{array}{l}\text { Increase coefficient of maturity or recruitment (per } \\
\text { year) }\end{array}$ \\
\hline$R_{\mathrm{MAX}}$ & Number of recruits at saturation level (fish) \\
\hline$R_{t}$ & Number of recruits (fish) \\
\hline$s$ & $\operatorname{Sex}(s=$ female, male $)$ \\
\hline$S_{s, a}$ & Proportion of recruited component to total \\
\hline$t$ & Calendar year $\left(t=1903,1904, \ldots, 2010=t_{\mathrm{MAX}}\right)$ \\
\hline$t_{M, 1}, t_{M, 2}$ & Year at beginning and end of span of changing $M_{0}$ \\
\hline$t_{R, 1}, t_{R, 2}$ & Year at beginning and end of span of changing $R_{\mathrm{MAX}}$ \\
\hline$t_{s}$ & First year of period for parameter estimation \\
\hline$t_{u, 1}, t_{u, 2}$ & Year at beginning and end of span of changing $u_{1, i, t, k}$ \\
\hline$u_{z, i, t, k}$ & CPUE (kg/effort) \\
\hline$v_{i}$ & Conversion parameter \\
\hline$w_{0}$ & Average body weight of glass eel $(\mathrm{kg})$ \\
\hline$w_{s, a}$ & Body weight at age $(\mathrm{kg})$ \\
\hline$W_{\infty, s}$ & Asymptotic weight of body (kg) \\
\hline$x(f)$ & $\begin{array}{l}\text { SPR (Spawning Stock (mature female) Per Recruit) } \\
\text { in steady state }\end{array}$ \\
\hline
\end{tabular}

Table 3 continued

\begin{tabular}{ll}
\hline Variable & Description \\
\hline$Y_{s, a, t}$ & Catch by age and sex (ton) \\
$Y_{z, t}$ & Annual catch (ton) \\
$y_{t}$ & Annual catch in the Lake Hamana \\
$z$ & Code of component of stock $(z=0$ for glass eels, \\
& $z=1$ for exploitable stock, and $z=2$ for stock of \\
$\alpha_{z, i, k}$ & affect of and older) \\
$\beta_{i, t}$ & Effect of year in logarithm of CPUE \\
$\chi_{i}$ & Shape parameter of negative binomial distribution \\
$\gamma_{0}, \gamma_{1}$ & Constant and coefficient in regression lines \\
$\delta_{i, t}$ & Probability of non zero catch in survey \\
$\varepsilon_{z, i, t, k}$ & Independent normal random error \\
$\varepsilon_{\mathrm{SR}, t}$ & Independent normal random error in logarithm of \\
$\eta_{t}$ & recruitment \\
$\kappa_{0, i}, \kappa_{1, i}$ & Correlated error in logarithm of recruitment \\
$v_{i, t}$ & Parameters in exponential coefficient \\
$\rho$ & Conditional mean of negative binomial distribution \\
$\sigma_{z, i}^{2}$ & Autoregressive parameter $(|\rho|<1)$ \\
$\sigma_{\mathrm{SR}}^{2}$ & Additional variance of error in CPUE series \\
$\xi_{i, m}$ & Variance of error in log $R_{t}$ \\
$\varsigma_{i, k}$ & Effect of month in logarithm of CPUE \\
\hline $\mathrm{CPUE}$ & Effect of site in logarithm of CPUE \\
\hline &
\end{tabular}

CPUE, Catch per unit effort

$$
\begin{aligned}
& R_{t}=g\left(B_{t}\right)=\frac{4 h R_{\mathrm{MAX}} d_{R}(t)}{(5 h-1)+\frac{(1-h) B_{\mathrm{MAX}}}{B_{t}}}, \\
& d_{M}(t)=\left\{\begin{array}{cc}
1 & \left(t=1903, \ldots, t_{M, 1}\right) \\
1+\left(p_{M}-1\right) \frac{t-t_{M, 1}}{t_{M, 2}-t_{M, 1}} & \left(t=t_{M, 1}+1, \ldots, t_{M, 2}\right) \\
p_{M} & \left(t=t_{M, 2}+1, \ldots, 2010\right),
\end{array}\right. \\
& d_{R}(t)=\left\{\begin{array}{cc}
1 & \left(t=1903, \ldots, t_{R, 1}\right) \\
1+\left(p_{R}-1\right) \frac{t-t_{R, 1}}{t_{R, 2}-t_{R, 1}} & \left(t=t_{R, 1}+1, \ldots, t_{R, 2}\right) \\
p_{R} & \left(t=t_{R, 2}+1, \ldots, 2010\right),
\end{array}\right.
\end{aligned}
$$

$B_{t}=\sum_{a=1} w_{\text {female }, a} m_{\text {female }, a-1} N_{\text {female }, a-1, t-1} \exp \left(-M_{a-1}-F_{\text {female }, a-1, t-1}\right)$,

$B_{\mathrm{MAX}}=\frac{1}{2} \sum_{a=1} w_{\mathrm{female}, a} m_{\mathrm{female}, a-1} R_{\mathrm{MAX}} \exp \left(-\sum_{i=1}^{a-1} M_{i}\right) \prod_{k=1}^{a-1}\left(1-m_{\mathrm{female}, k-1}\right)$,

$m_{s, a}= \begin{cases}0 & (a=0,1) \\ \frac{1}{1+\exp \left\{-r_{m, s}\left(a-a_{m, s}\right)\right\}} & \left(a=2, \ldots, a_{\mathrm{MAX}}\right),\end{cases}$ 
$S_{s, a}= \begin{cases}1 & (a=0) \\ \frac{1}{1+\exp \left\{-r_{S, s}\left(a-a_{S, s}\right)\right\}} & \left(a=1, \ldots, a_{\mathrm{MAX}}\right)\end{cases}$

$w_{s, a}= \begin{cases}w_{0} & (a=0) \\ W_{\infty, s}\left[1-\exp \left\{-K_{s}\left(a-a_{0, s}\right)\right\}\right]^{b} & \left(a=1, \ldots, a_{\mathrm{MAX}}\right) .\end{cases}$

Here $d_{M}(t)$ and $d_{R}(t)$ are introduced to express annual changes in $M_{0}$ and $R_{\text {MAX }}$ to observe the effect of habitat loss or environmental changes, and are used only for the sensitivity tests $\left(p_{M}=p_{R}=1\right.$ as base case).

For incorporating stochastic effect in the number of recruits due to environmental fluctuation into the models, the following error structure was introduced:

$\ln \left(R_{t}\right)=\ln \left\{g\left(B_{t-1}\right)\right\}+\eta_{t}$

$\eta_{t}=\varepsilon_{\mathrm{SR}, t}+\rho \eta_{t-1}$

$\varepsilon_{\mathrm{SR}, t} \sim N\left(0, \sigma_{\mathrm{SR}}^{2}\right)$

The model assuming $\rho=0$ was used as the base case and the AR (1) (autoregressive of order 1) model such as $\rho \neq 0$ was used only for the sensitivity tests.

\section{Biological parameters}

Table 4 shows the values of the biological and operational parameters used for estimations under the base case scenario (S1) that uses a standard data set. Parameter values, with the exception of natural mortality coefficients and parameters in the selectivity function, are estimates for eels in the Tone River, Chiba Prefecture [21]. Values of natural mortality coefficients in Table 4 are assumed from values used to indicate values of European eels [38-41], and the values of parameters in the selectivity function are assumed from the shape of the length frequency in the catch [21].

\section{Log-likelihoods}

Given parameters values in growth, maturity and gear selectivity $\left(W_{\infty, s}, K_{s}, a_{0, s}, b, M_{a}, r_{m, s}, a_{m, s}, r_{S, s}, a_{S, s}\right)$, unknown parameters were estimated by maximizing the log-likelihood of standardized CPUE for exploitable stock and the glass eels and stock-recruitment relationship

$l=\sum_{n=1}^{3} l_{n}$

Log-likelihoods using the standardized CPUE for exploitable stock and glass eels are expressed by
Table 4 Values of biological parameters used for estimations in the base case scenario (S1)

\begin{tabular}{llll}
\hline Category & Notation & \multicolumn{2}{l}{ Value } \\
\cline { 3 - 4 } & & Male & Female \\
\hline Growth parameters & $w_{0}(\mathrm{~g})$ & 0.15 & 0.15 \\
& $W_{\infty, s}(\mathrm{~g})$ & 372.4 & $1,365.1$ \\
& $K_{s}(1 /$ year $)$ & 0.18 & 0.13 \\
& $a_{0, s}$ (year) & -1.07 & -1.14 \\
& $b_{w, s}$ & 3.42 & 3.42 \\
Maturity & $r_{m s}(1 /$ year $)$ & 1.47 & 1.47 \\
Selectivity & $a_{m, s}($ year $)$ & 5.00 & 9.00 \\
& $r_{S}(1 /$ year $)$ & 2.94 & 2.94 \\
Natural mortality coefficient & $a_{S, s}$ (year) & 2.50 & 2.50 \\
& $M_{0}(1 /$ half of year $)$ & 3.40 & 3.40 \\
& $M_{1}(1 /$ year $)$ & 0.20 & 0.20 \\
& $M_{2}(1 /$ year $)$ & 0.10 & 0.10 \\
& $M_{a}(a>2,1 /$ year $)$ & 0.05 & 0.05 \\
\end{tabular}

Calculated from the estimated equations of growth of length and length-weight relationship

$$
\begin{aligned}
& l_{1}=-\frac{1}{2} \sum_{i=1}^{2} \sum_{t}\left[\ln \left\{2 \pi\left(\mathrm{V}\left[\ln \left(u_{1, i, t, *}\right)\right]+\hat{\sigma}_{1, i}^{2}\right)\right\}\right. \\
& \left.+\frac{\left\{\ln \left(\mathrm{E}\left[u_{1, i, t, *}\right] / d_{u}(t)\right)-\ln \left(q_{1, i, t} P_{t}\right)\right\}^{2}}{\mathrm{~V}\left[\ln \left(u_{1, i, t, *}\right)\right]+\hat{\sigma}_{1, i}^{2}}\right] \text {, } \\
& l_{2}=-\frac{1}{2} \sum_{i=1}^{3} \sum_{t}\left[\ln \left(2 \pi \mathrm{V}\left[\ln \left(u_{0, i, t, *}\right)+\hat{\sigma}_{0, i}^{2}\right]\right)\right. \\
& \left.+\frac{\left.\left\{\ln \left(\mathrm{E}\left[u_{0, i, t, *}\right] / d_{u}(t)\right)-\ln \left(\hat{q}_{0, i} v_{i} R_{t}\right)\right\}^{2}\right]}{\mathrm{V}\left[\ln \left(u_{0, i, t, *}\right)\right]+\hat{\sigma}_{0, i}^{2}}\right], \\
& q_{1,1, t}= \begin{cases}\hat{q}_{1,1} & \left(t=t_{s}, \ldots, t_{c}-1\right) \\
\hat{q}_{1,1}^{\prime} & \left(t=t_{c}, \ldots, 2006\right),\end{cases} \\
& v_{i}=\left\{\begin{array}{lll}
w_{0} & (i=1) & (27 \mathrm{a}) \\
1 & (i=2,3), & (27 \mathrm{~b})
\end{array}\right. \\
& d_{u}(t)=\left\{\begin{array}{cc}
1 & \left(t=1903, \ldots, t_{u, 1}\right) \\
1+\left(p_{u}-1\right) \frac{t-t_{R, 1}}{t_{R, 2}-t_{R, 1}} & \left(t=t_{u, 1}+1, \ldots, t_{u, 2}\right) \\
p_{u} & \left(t=t_{u, 2}+1, \ldots, 2010\right) .
\end{array}\right.
\end{aligned}
$$

Here $d_{u}(t)$ is the factor correcting effect of river development on CPUE and is used only for the sensitivity tests $\left(p_{u}=1\right.$ as base case). Log-likelihood for stock and recruitment is expressed by

$$
\begin{aligned}
& l_{3}=-\frac{1}{2} \ln \left\{2 \pi \hat{\sigma}_{S R}^{2} /(1-\hat{\rho})\right\}+\frac{\left\{\ln \left(R_{t_{s}}\right)-\ln \left(g\left(B_{t_{s}-1}\right)\right)\right\}^{2}}{\hat{\sigma}_{S R}^{2} /(1-\hat{\rho})} \\
& -\frac{1}{2} \sum_{t=t_{s}+1}\left[\ln \left(2 \pi \hat{\sigma}_{S R}^{2}\right)+\frac{\left\{\ln \left(R_{t}\right)-\ln \left(g\left(B_{t-1}\right)\right)-\hat{\rho}\left(\ln \left(R_{t-1}\right)-\ln \left(g\left(B_{t-2}\right)\right)\right)\right\}^{2}}{\hat{\sigma}_{S R}^{2}}\right] .
\end{aligned}
$$


Estimation in the base case scenario is carried out by taking $\hat{\rho}=0$ in Eq. 29.

\section{Estimation procedures}

The period of available data was separated into the first and second periods, that is, $t=1903, \ldots, t_{s}-1\left(t_{s}=\right.$ 1954) and $t=t_{s}, \ldots, t_{\mathrm{MAX}}(=2010)$. In the first period only the catch data were available, and in the second period, standardized CPUE for exploitable stock and glass eels were added to the statistical model. Although estimations can be conducted only by dataset in the second $f_{z, t}=-\ln \left(1-\frac{Y_{z, t}}{P_{z, t}}\right) \quad\left(t=1904, \ldots, t_{s}-1\right)$,

and values of $N_{s, a, t_{s}}$ are recursively computed.

In the second period, $f_{0, t}$ is the parameter to be estimated, and the value of $R_{t}$ was estimated by dividing the catch by the exploitation rate:

$R_{t}=\frac{Y_{0, t}}{w_{0}\left\{1-\exp \left(-f_{0, t}\right)\right\}}$.

In order to reduce the number of parameters to be estimated, assuming linear changes in $f_{0, t}$ for an interval of 3 years, $f_{0, t}$ is expressed by

$$
f_{0, t}= \begin{cases}\hat{f}_{0, t} & \left(t=t_{s}+3 v-1, v=1,2, \cdots\right) \\ f_{0, t_{s}-1}+\frac{\left(t-t_{s}+1\right)}{3}\left(\hat{f}_{0, t_{s}+1}-f_{0, t_{s}-1}\right) & \left(t=t_{s}, t_{s}+1\right) \\ \hat{f}_{0, t_{s}+3 v-1}+\frac{\left(t-t_{s}-3 v+1\right)}{3}\left(\hat{f}_{0, t_{s}+3 v+2}-\hat{f}_{0, t_{s}+3 v-1}\right) & (\text { elsewhere }) .\end{cases}
$$

period, catch data in the first period were used to reflect the effect of catch during the first period in the estimates of $N_{s, a, t}$ at $t=t_{s}$. Assuming the stock was in a steady state before $t=1903$ and that $\sigma_{\mathrm{SR}}^{2}=0$ over the first period, $N_{s, a, t_{s}}$ can be projected using deterministic models expressed by Eqs. 1a-14c.

Glass eel stock was not exploited before 1903 and from the steady state assumption $N_{s, a, 1903}$ is expressed by

$$
N_{s, a, 1903}= \begin{cases}\frac{1}{2} R_{1} & (a=0) \\ \frac{1}{2} R_{1} \exp \left\{-\sum_{n=0}^{a-1}\left(M_{n}+F_{s, n-1,1}\right)\right\} & \\ \prod_{n=1}^{a-1}\left(1-m_{s, n-1}\right) & \left(a=1, \ldots, a_{\mathrm{MAX}}\right) .\end{cases}
$$

Given the data on $Y_{1,1903}$ and the values of $\hat{R}_{\mathrm{MAX}}$ and $\hat{h}$, the value of $f_{1,1903}$ is uniquely determined by solving the following simultaneous equations:

$$
\begin{aligned}
& R_{1903}=\frac{\hat{R}_{\mathrm{MAX}}}{5 h-1}\left\{4 \hat{h}-(1-\hat{h}) \frac{x(0)}{x\left(f_{1,1903}\right)}\right\}, \\
& Y_{1,1903}=R_{1903} x\left(f_{0,1903}\right)\left\{1-\exp \left(-f_{1,1903}\right)\right\}, \\
& x(f)=\frac{1}{2} \sum_{a=1} w_{\text {female }, a} \exp \left\{-\sum_{n=0}^{a-1}\left(M_{n}\right)\right\} \prod_{n=1}^{a-1} \\
& \left(1-m_{\text {female }, n-1}\right)\left[1-S_{\text {female }, n-1}\{1-\exp (-f)\}\right] .
\end{aligned}
$$

After 1904, the value of $f_{z, t}$ is deterministically computed by
Unknown parameters $\left(\hat{R}_{\mathrm{MAX}}, \hat{h}, \hat{f}_{0, t_{s}+3 v-1}, \hat{q}_{1,1}, \hat{q}_{1,1}^{\prime}, \hat{q}_{0, j}\right.$, $\left.\hat{\sigma}_{z, i}^{2}, \hat{\sigma}_{\mathrm{SR}}^{2}, \hat{\rho}\right)$ maximizing Eq. 23 are numerically searched for under the following constraints on variances:

$\frac{\partial l}{\partial \hat{\sigma}_{z, i}^{2}}=\frac{\partial l}{\partial \hat{\sigma}_{\mathrm{SR}}^{2}}=0$.

Values of $95 \% \mathrm{CL}$ are computed using the inverse of the Fisher information matrix [42] and the delta method [43].

For the sensitivity tests, estimations were conducted for 18 scenarios as tabulated in Table 5 where S1, S2-S6, S7-S13 and S14-S18 show the base case, cases of different natural mortalities, cases of different biological parameters and cases of different data sets, respectively. S6 or S13 indicate cases where $M_{0}$ or $R_{\mathrm{MAX}}$ has increased or declined due to environmental change and/or anthropogenic impact. S14 represents a situation where a decrease in eel density in Lakes Kasumigaura and Kitaura was caused by the variable effect of the floodgate as estuarial barrier since the construction and operation started in 1963 and 1974, respectively. Note that if S14 is true, S1 (base case scenario) indicates the pessimistic scenario. S18 is introduced to exclude the effect of the inherent dynamics of CPUE in these lakes.

Application of results of estimations

To compare the production from fisheries with aquaculture production using glass eels, I illustrate sustainable yield curves using parameter estimates for two extreme cases, in which 
Table 5 Scenarios for parameter estimation

\begin{tabular}{|c|c|c|}
\hline $\begin{array}{l}\text { Code } \\
\text { number }\end{array}$ & Scenario & Description \\
\hline S1 & Base case & $\rho=0, p_{M}=p_{R}=p_{u}=1$ \\
\hline $\mathrm{S} 2$ & Small $M_{0}$ & $M_{0}=2.9$ (per half year $)$ \\
\hline S3 & Large $M_{0}$ & $M_{0}=3.9$ (per half year $)$ \\
\hline S4 & $\begin{array}{c}0.5 M_{a} \text { and } \\
M_{0}=2.9\end{array}$ & $50 \%$ of $M_{a}(a \geq 1)$ and $M_{0}=2.9$ \\
\hline S5 & $\begin{array}{c}1.5 M_{a} \text { and } \\
M_{0}=3.9\end{array}$ & $150 \%$ of $M_{a}(a \geq 1)$ and $M_{0}=3.9$ \\
\hline S6 & $M_{0}(t)$ & $p_{M}=1.5, t_{M, 1}=1970, t_{M, 2}=2000$ \\
\hline S7 & $0.7 W_{\infty, s}$ & $70 \%$ of $W_{\infty, s}$ in base case \\
\hline S8 & $S_{a}$ shift & $a_{S, \text { male }}=4.5, a_{S, \text { female }}=4$ \\
\hline S9 & $m_{a}$ shift & $a_{m, \text { male }}=5.5, a_{m, \mathrm{female}}=10$ \\
\hline S10 & AR (1) & $\rho$ is estimated \\
\hline S11 & $h=0.3$ & $h=0.3$ \\
\hline $\mathrm{S} 12$ & $h=0.8$ & $h=0.8$ \\
\hline $\mathrm{S} 13$ & $R_{\text {MAX }}$ decrease & $p_{R}=0.3, t_{R, 1}=1970, t_{R, 2}=2010$ \\
\hline S14 & $\begin{array}{l}\text { CPUE } \\
\text { corrected }\end{array}$ & $p_{u}=0.3, t_{u, 1}=1963, t_{u, 2}=1981$ \\
\hline S15 & $\begin{array}{l}\text { Underreported } \\
\text { catch A }\end{array}$ & $150 \%$ of catch for glass eels is true \\
\hline S16 & $\begin{array}{l}\text { Underreported } \\
\text { catch B }\end{array}$ & $\begin{array}{l}150 \% \text { of catch for exploitable stock is } \\
\text { true }\end{array}$ \\
\hline S17 & $\begin{array}{l}\text { Underreported } \\
\text { catch C }\end{array}$ & $150 \%$ of catch for all stocks is true \\
\hline $\mathrm{S} 18$ & $\begin{array}{l}\text { Excluding one } \\
\text { CPUE }\end{array}$ & $\begin{array}{l}\text { CPUE in the Lakes Kasumigaura and } \\
\text { Kitaura is excluded }\end{array}$ \\
\hline
\end{tabular}

AR (1) model, autoregressive of order 1 model

either takes of exploitable stock or glass eels are permitted, respectively. Using the curves, I computed maximum sustainable yield (MSY) to consider the strategy of stock management.

\section{Results}

The results of the estimation for the base case scenario are summarized in Table 6 and Figs. 4-8. Table 6 shows the values of the parameter estimate and indicates that the value of $\hat{h}$ was 0.66 (95\% CL $0.21-0.89$ ), that of $\hat{P}_{2,2010}$ (stock size of individuals aged $\geq 1$ year) was 18.7 (95\% CL 9.2-28.4) thousand tons and that of $\hat{P}_{2,2010} / K$ was $24 \%$ of the initial size (5-44\%).

Figures 4 and 5 compare data and MLE of CPUE in the base case scenario. In CPUE for exploitable stock in Lake Kasumigaura and Kitaura, there was a discrepancy in the second half of the 1980s between the data and the estimates, suggesting the existence of locality of stock abundance in the data. Comparison of three series of CPUE for glass eels revealed that the goodness of fit of estimates to data of commercial fisheries were better than those of the
Table 6 Parameter estimates for the base case scenario (S1)

\begin{tabular}{|c|c|c|c|}
\hline Parameter & $\begin{array}{l}\text { Point } \\
\text { estimates }\end{array}$ & $\begin{array}{l}\text { Lower } 95 \% \\
\text { CL }\end{array}$ & $\begin{array}{l}\text { Upper } 95 \% \\
\text { CL }\end{array}$ \\
\hline$R_{\max }$ (million fish) & $3,435.8$ & $2,259.9$ & $5,223.6$ \\
\hline$h$ & 0.662 & 0.214 & 0.894 \\
\hline$f_{0,1956}$ (per year) & 0.285 & 0.178 & 0.456 \\
\hline$f_{0,1959}$ (per year) & 0.452 & 0.285 & 0.717 \\
\hline$f_{0,1962}$ (per year) & 0.561 & 0.366 & 0.861 \\
\hline$f_{0,1965}$ (per year) & 0.308 & 0.183 & 0.517 \\
\hline$f_{0,1968}$ (per year) & 0.284 & 0.174 & 0.466 \\
\hline$f_{0,1971}$ (per year) & 0.654 & 0.445 & 0.961 \\
\hline$f_{0,1974}$ (per year) & 0.322 & 0.215 & 0.482 \\
\hline$f_{0,1977}$ (per year) & 0.729 & 0.481 & 1.104 \\
\hline$f_{0,1980}$ (per year) & 0.516 & 0.386 & 0.690 \\
\hline$f_{0,1983}$ (per year) & 0.691 & 0.529 & 0.901 \\
\hline$f_{0,1986}$ (per year) & 0.514 & 0.365 & 0.724 \\
\hline$f_{0,1989}$ (per year) & 0.594 & 0.395 & 0.892 \\
\hline$f_{0,1992}$ (per year) & 0.503 & 0.333 & 0.760 \\
\hline$f_{0,1995}$ (per year) & 0.847 & 0.565 & 1.268 \\
\hline$f_{0,1998}$ (per year) & 0.433 & 0.211 & 0.890 \\
\hline$f_{0,2001}$ (per year) & 0.747 & 0.396 & 1.409 \\
\hline$f_{0,2004}$ (per year) & 0.480 & 0.270 & 0.852 \\
\hline$f_{0,2007}$ (per year) & 0.487 & 0.258 & 0.920 \\
\hline$f_{0,2010}($ per year) & 0.346 & 0.178 & 0.671 \\
\hline $\begin{array}{l}q_{1,1}\left(\times 10^{-6}, \text { per day- }\right. \\
\text { boat })\end{array}$ & 0.016 & 0.011 & 0.021 \\
\hline $\begin{array}{l}q_{1,1}^{\prime}\left(\times 10^{-6} \text {, per day- }\right. \\
\text { boat })\end{array}$ & 0.012 & 0.007 & 0.022 \\
\hline $\begin{array}{l}q_{1,2}\left(\times 10^{-3} \text {, per fishing }\right. \\
\text { unit })\end{array}$ & 0.021 & 0.014 & 0.032 \\
\hline $\begin{array}{l}q_{0,1}\left(\times 10^{-6}, \text { per day- }\right. \\
\text { gear })\end{array}$ & 0.012 & 0.007 & 0.022 \\
\hline $\begin{array}{l}q_{0,2}\left(\times 10^{-6} \text {, per day- }\right. \\
\text { gear })\end{array}$ & 0.015 & 0.009 & 0.026 \\
\hline $\begin{array}{l}q_{0,3}\left(\times 10^{-6}, \text { per day- }\right. \\
\text { fisher })\end{array}$ & 0.035 & 0.008 & 0.153 \\
\hline$\sigma_{1,1}$ & 1.405 & 1.128 & 1.750 \\
\hline$\sigma_{1,2}$ & 1.376 & 0.834 & 2.269 \\
\hline$\sigma_{0,1}$ & 3.991 & 2.669 & 5.970 \\
\hline$\sigma_{0,2}$ & 1.221 & 1.133 & 1.316 \\
\hline$\sigma_{\mathrm{SR}}$ & 1.376 & 0.834 & 2.269 \\
\hline
\end{tabular}

CL, Confidence limit

abundance survey due to the difference in the magnitude of variability in the data between the series. Figure 6 illustrates $\hat{R}_{t}$ against $\hat{B}_{t}$, and Figs. 7 and 8 show annual changes in $\hat{E}_{z, t}$ and $\hat{P}_{z, t}$, respectively. From these figures, it can be seen that the recent value of $\hat{E}_{0, t}(43 \%$ in $\mathrm{S} 1)$ is much larger than that of $\hat{E}_{1, t}(2.2 \%)$ and that $\hat{P}_{2, t}$ has recovered since about 1990 because of a reduction of the exploitation rate by fisheries. 
(a) Lakes Kasumigaura and Kitaura
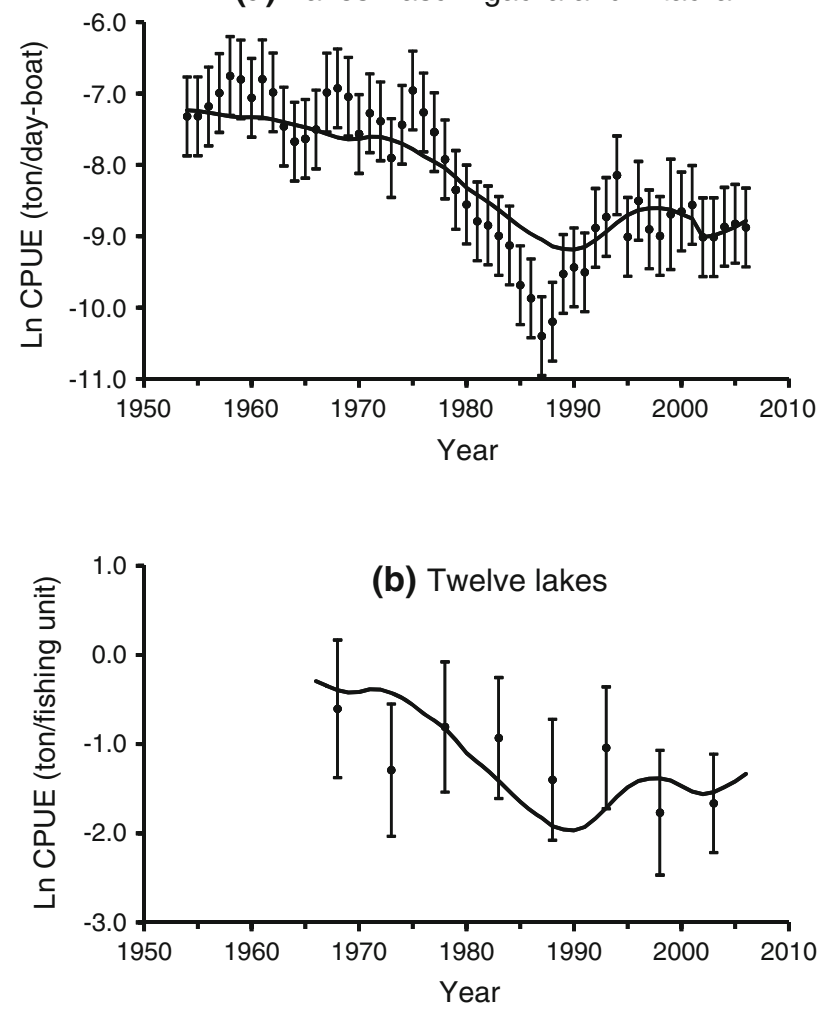

Fig. 4 Data and estimated series of natural logarithm of standardized commercial catch per unit effort $(C P U E)$ for exploitable stock. Base case scenario: vertical bars $95 \%$ intervals of standardized CPUE, curves estimated trajectories of the CPUE

The results of the sensitivity tests are summarized in Table 7. This table shows that the value of $M_{0}$ was sensitive to the absolute values of $\hat{P}_{2, t}$ and that a small $M_{0}$ value causes large values for both $\hat{P}_{2, t}$ and $\hat{E}_{0, t}$; therefore, the value of $M_{0}$ used in the base case scenario (S1) produced relatively consistent results of estimation. If the catch was underreported, $\hat{P}_{2, t}$ from $\mathrm{S} 1$ is underbiased and used only as precautional values in regulation of catch amount.

Comparison of the trajectories of $\hat{P}_{2, t}$ across all scenarios is shown in Fig. 9. This figure suggests that the shape of the trajectory was similar across all the scenarios, even if CPUE in Lake Kasumigaura and Kitaura was removed from the model (S18) and that the recent trend of $\hat{P}_{2, t}$ was similar in all the scenarios.

On observing the trajectories from scenario S6 to $\mathrm{S} 13$ in the figure, it can be seen that the decline of $\hat{P}_{2, t}$ over the 1960s and 1970s was rapid in comparison with that of the other scenarios and that the goodness of fit to the data from stock and recruitment improved to such an extent that S6 and S13 realized a greater value of the total of log-likelihood (Table 7). The results suggest that there was a potential external factor affecting glass eels.

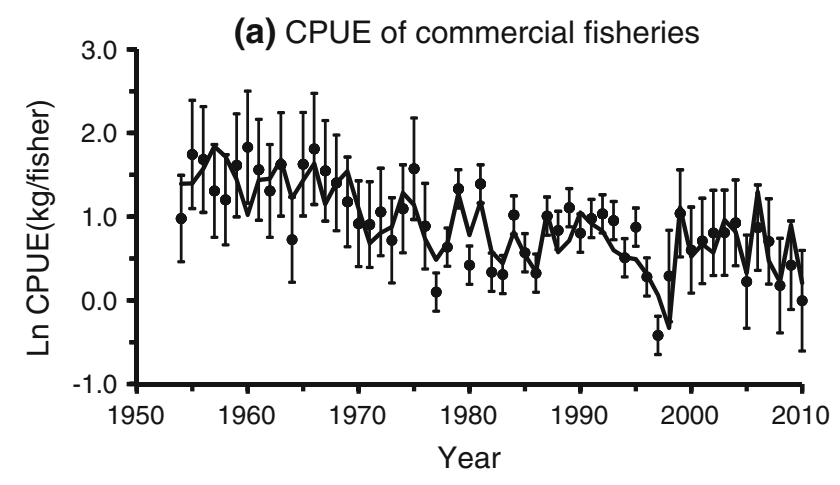

(b) CPUE of abundance survey

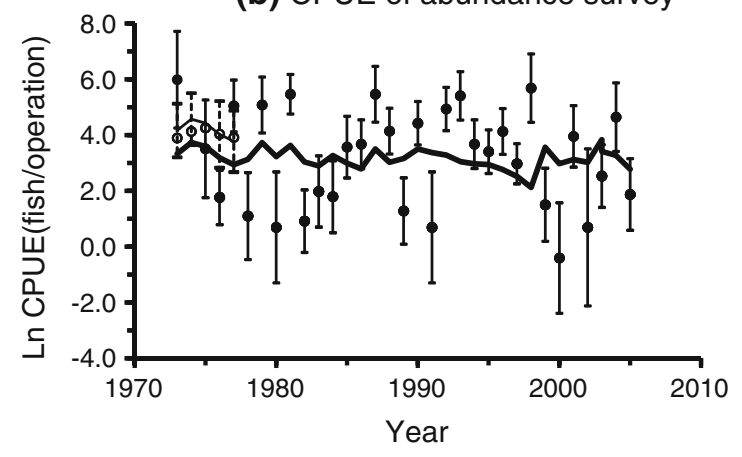

Fig. 5 Data and estimated series of natural logarithm of standardized commercial CPUE for glass eels. Base case scenario: vertical bars $95 \%$ intervals of standardized CPUE, curves estimated trajectories of the CPUE

Figure 10 illustrates the sustainable yield against $\hat{P}_{2, t}$. When utilization of exploitable stock was allowed for the fisheries, the value of MSY was 4,180 tons and the value of fishing coefficient giving the MSY was 0.11 (per year). When only glass eels were permitted for aquaculture, the MSY value was 266 tons.

\section{Discussion}

Under various scenarios, the results of the estimation firmly supported the recent recovery of $\hat{P}_{2, t}$. It was hypothesized that the recovery would be caused by the reduction of scale of eel fisheries, as discussed earlier. Since the main fishing gears for catching eel stock are traditional and conservative, a decrease in the number of fishing units would therefore contribute significantly to the reduction of excess effort.

To understand the unified effect of two fishing mortalities $\left(f_{0, t}\right.$ and $\left.f_{1, t}\right)$ to the exploitable stock, the value of $f_{0, t}$ is converted to that of $f_{1, t}$, giving the same spawning per recruit $\left(x\left(f_{1, t}\right)\right)$. In the biological and operational parameters in the base case scenario (S1), the unified value is approximately expressed by $f_{1, t}+0.123 f_{0, t}$. The averages 


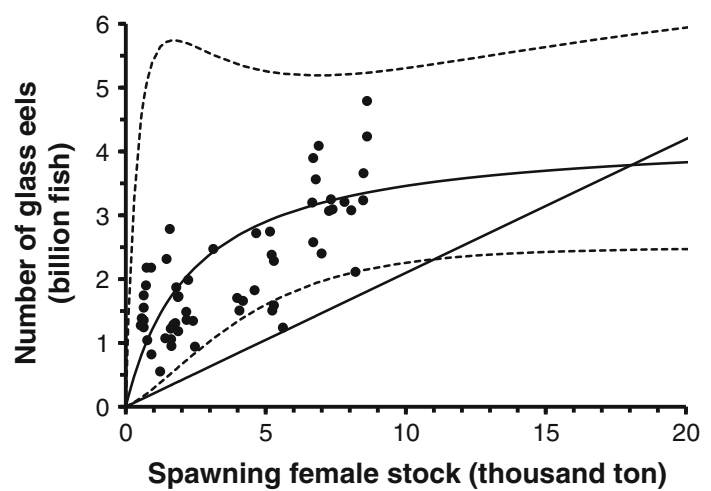

Fig. 6 Estimated stock and recruitment in base case scenario Filled circles, solid-line curve and dotted-line curves Point estimates, estimated curve and upper and lower $95 \%$ confidence intervals, respectively
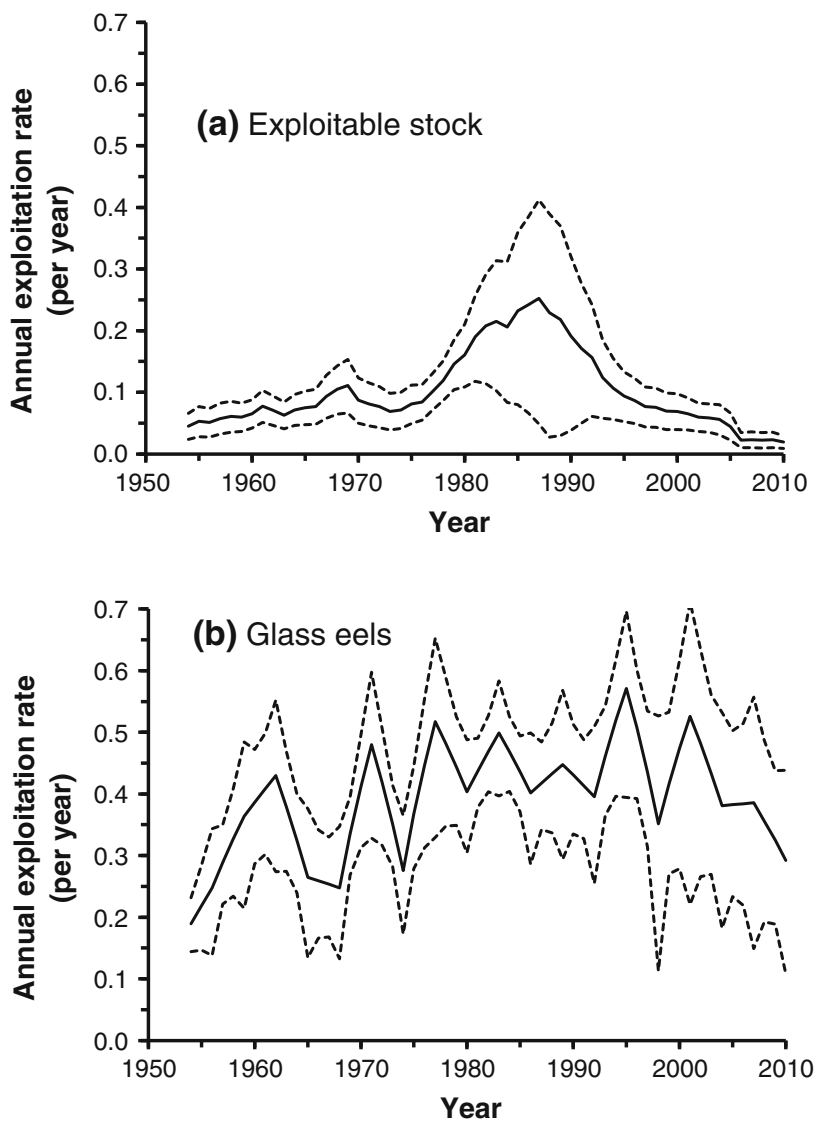

Fig. 7 Estimated trajectories of exploitation rates of exploitable stock and glass eels in base case scenario. Solid-line and dotted-line curves Point estimate and upper and lower $95 \%$ confidence limits, respectively

of $f_{1, t}+0.123 f_{0, t}$ for the 1950s, 1960s, 1970s, 1980s, $1990 \mathrm{~s}$, and $2000 \mathrm{~s}$ were $0.09,0.14,0.17,0.32,0.18$, and 0.10 , respectively. The average for the 2000 s was slightly less than $f_{1, t}=0.11$, giving the MSY.
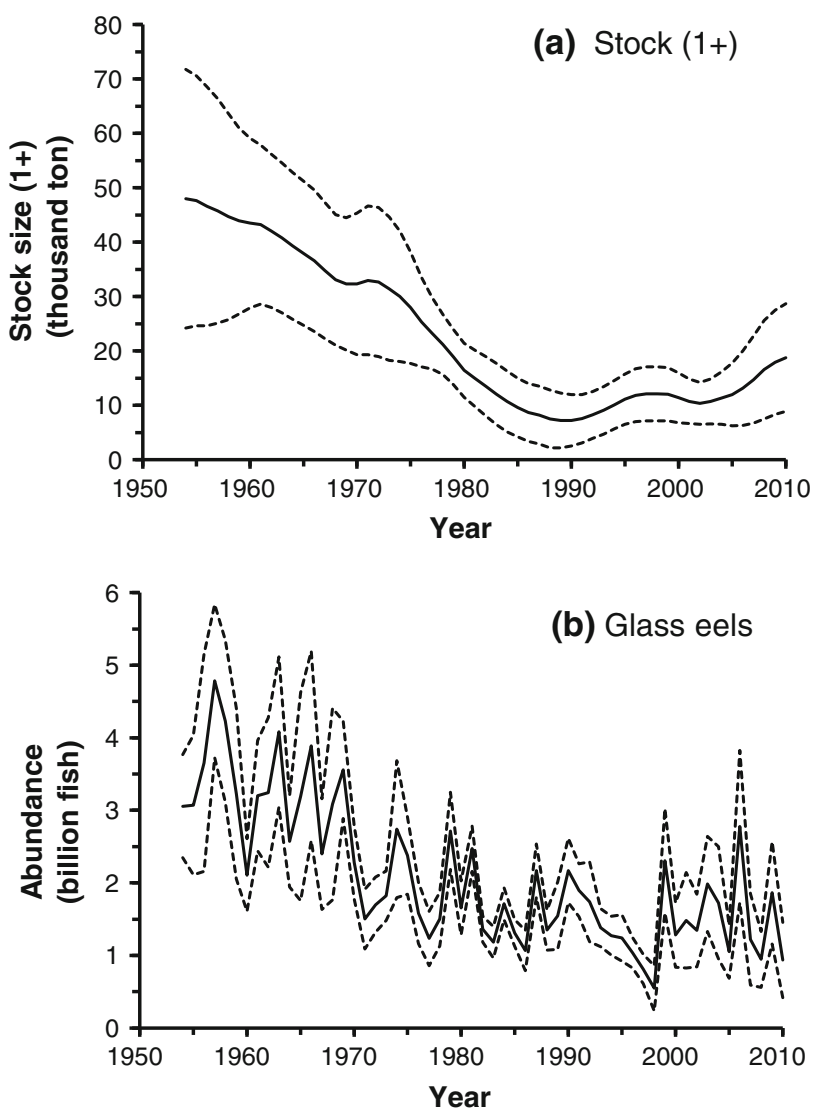

Fig. 8 Estimated trajectories of size of stock $(1+$ group $)$ and glass eels in base case scenario. Solid-line and dotted-line curves Point estimate and upper and lower $95 \%$ confidence limits, respectively

In the sensitivity tests, S15-S17 cover the entire plausible range and, consequently, the underreported catch does not affect the present results. It is a possibility that Japanese statistics do not include part of the catch in the coastal zone [44]; however, the effect of the catch is small because the scale of fisheries exploiting the stock in the sea is relatively tiny compared to that in freshwater fisheries.

Using ad hoc data to calculate the rate of the annual aquaculture production to the annual input of utilization of glass eels as seeds (for example, 690 times for Chinese aquaculture), the recent Chinese input of glass eels was estimated to be sevenfold the total amount adopted in our study. The estimate of total takes of glass eels in East Asia has increased since the 1970s; however, the increase has been quite inconsistent with respect to the decreased input of glass eels in each of the countries and regions. Thus, data on eel stock should be carefully examined.

A potential for overreported takes of glass eels in Japanese statistics was presented when the annual demand of glass eels was estimated by converting aquaculture production of commercial size eels to constant survival and growth rates [45]. However, in general, demand does not 
Table 7 Summary of results for sensitivity tests

\begin{tabular}{|c|c|c|c|c|c|c|c|c|c|c|c|c|}
\hline Code number & $l$ & $l_{1}$ & $l_{2}$ & $l_{3}$ & $p^{\mathrm{a}}$ & $R_{\max }$ (million fish) & $h$ & $f_{0, *}^{b}$ & $f_{1, *}^{b}$ & $P_{1980} / K_{t}$ & $P_{1980}$ (ton) & $P_{2010}$ (ton) \\
\hline S1 & -145.8 & -38.3 & -77.3 & -30.2 & 32 & 3,436 & 0.662 & 0.430 & 0.022 & 0.241 & 16,453 & 18,783 \\
\hline S2 & -145.4 & -48.2 & -76.0 & -21.3 & 32 & 2,931 & 0.547 & 0.509 & 0.013 & 0.268 & 26,028 & 29,257 \\
\hline $\mathrm{S} 3$ & -152.7 & -43.9 & -77.2 & -31.6 & 32 & 8,782 & 0.383 & 0.247 & 0.015 & 0.221 & 24,117 & 26,175 \\
\hline S4 & -145.2 & -44.7 & -75.6 & -24.9 & 32 & 2,826 & 0.506 & 0.660 & 0.013 & 0.213 & 33,618 & 28,496 \\
\hline S5 & -153.6 & -42.3 & -77.5 & -33.9 & 32 & 9,538 & 0.424 & 0.213 & 0.016 & 0.233 & 20,916 & 24,287 \\
\hline S6 & -136.6 & -36.8 & -75.3 & -24.5 & 32 & 4,771 & 0.902 & 0.197 & 0.042 & 0.087 & 23,580 & 9,417 \\
\hline S7 & -152.8 & -39.4 & -77.6 & -35.8 & 32 & 4,344 & 0.640 & 0.348 & 0.024 & 0.247 & 16,075 & 17,093 \\
\hline S8 & -145.0 & -42.1 & -77.7 & -25.2 & 32 & 3,092 & 0.665 & 0.466 & 0.025 & 0.249 & 15,963 & 17,454 \\
\hline S9 & -141.8 & -40.1 & -77.0 & -24.7 & 32 & 3,147 & 0.650 & 0.483 & 0.020 & 0.231 & 19,553 & 20,886 \\
\hline S10 & -140.2 & -38.3 & -77.3 & -24.7 & 33 & 3,398 & 0.665 & 0.432 & 0.022 & 0.242 & 16,321 & 18,685 \\
\hline S11 & -154.9 & -40.9 & -77.5 & -36.5 & 31 & 8,456 & 0.300 & 0.375 & 0.012 & 0.155 & 35,635 & 29,654 \\
\hline S12 & -145.8 & -37.0 & -78.2 & -30.7 & 31 & 2,874 & 0.800 & 0.433 & 0.023 & 0.281 & 14,101 & 18,311 \\
\hline S13 & -135.7 & -37.0 & -75.8 & -23.0 & 32 & 4,313 & 0.770 & 0.453 & 0.021 & 0.661 & 20,724 & 19,394 \\
\hline S14 & -152.8 & -45.9 & -75.7 & -31.3 & 32 & 4,484 & 0.497 & 0.426 & 0.018 & 0.222 & 21,644 & 22,561 \\
\hline S15 & -141.5 & -39.9 & -76.8 & -24.9 & 32 & 4,274 & 0.654 & 0.443 & 0.019 & 0.217 & 19,507 & 21,030 \\
\hline S16 & -151.0 & -39.8 & -77.9 & -33.3 & 32 & 4,579 & 0.657 & 0.311 & 0.022 & 0.272 & 22,931 & 28,215 \\
\hline S17 & -145.6 & -37.8 & -77.0 & -30.8 & 32 & 5,708 & 0.641 & 0.321 & 0.020 & 0.241 & 26,674 & 31,155 \\
\hline S18 & -100.0 & -3.9 & -76.2 & -19.8 & 32 & 4,599 & 0.448 & 0.347 & 0.013 & 0.289 & 19,385 & 30,191 \\
\hline
\end{tabular}

a Number of parameters to be estimated

b Average over recent 5 years

reflect supply. For example, in the 1950s-1960s, the eel aquaculture industry consisted of two types of companies; one is to produce the seed $(5-20 \mathrm{~g})$ with glass eels and the other is to produce eels of commercial size (150-200 g) by buying the seeds and obtaining natural ones [2, 4]. Under conditions of open competition, some overproduction of the seeds would occur. Note that the price of glass eels corrected by deflator in 1960 was around $5 \%$ of the price in 2010 and that the fast-growing seeds were selected and landed a few times in the landing season. A similar discrepancy between the theoretical demand for glass eels and the actual supply has been acknowledged [46]. In addition, values of survival and growth rates dramatically improved due to technical progress around 1970.

An abundance index representing the total abundance in East Asia is desirable when the aim is to make successive estimations. Although the best available Japanese data have been used in our calculations, additional evidence may be needed to confirm that the data do not involve bias in the trend for CPUE due to Japanese regionality of stock density. The regionality of stock density among countries is caused by differences in the annual exploitation rate for both exploitable stock and glass eels, and by the regional quantity of glass eels transported by ocean currents. Research surveys on stock abundance in other countries are necessary in the near future to investigate the issue of regionality.
If stock is divided into two substocks (Japanese and another substock) and a parameter of the rate of the Japanese substock of glass eel to the whole amount is introduced, population dynamics by substock can be theoretically simulated. This would enable the expression of differences in the abundance index of exploitable stock between waters where the stock is exploited and where it is not. In general, dynamical models for stock consisting of several substocks are available. However, this approach is currently premature because there is no information available to compare sizes of the substocks and this parameter will be sensitive to the results of assessment.

CPUE for exploitable stock may be affected by river development, and the correction of CPUE may be necessary if a gap in annual changes of CPUE exists between the whole stock and the local stock in the lake. Although variable effects of floodgates may have caused the decline of catch amount in Lake Kasumigaura and Kitaura [35], the correction in S14 does not contribute to this likelihood, and the effect does not seem remarkable as compared to S6 and S13. In the Tone river system, including the lakes, (1) the annual takes of glass eels in the mouth of the river seemed to be fluctuating around the constant mean during 1963-2005 and (2) both total catch in the river system for glass eels and exploitable stock decreased [35]. If the effect of river development was presumed due to the local 


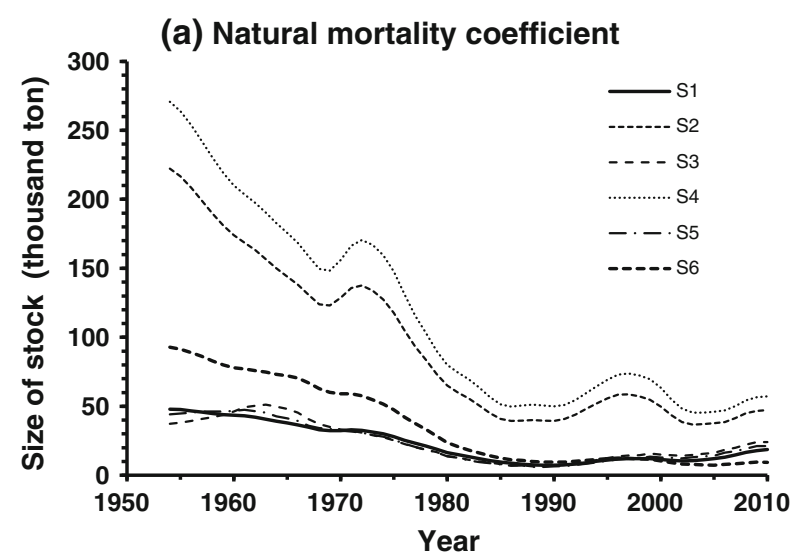

(b) Other biological parameters
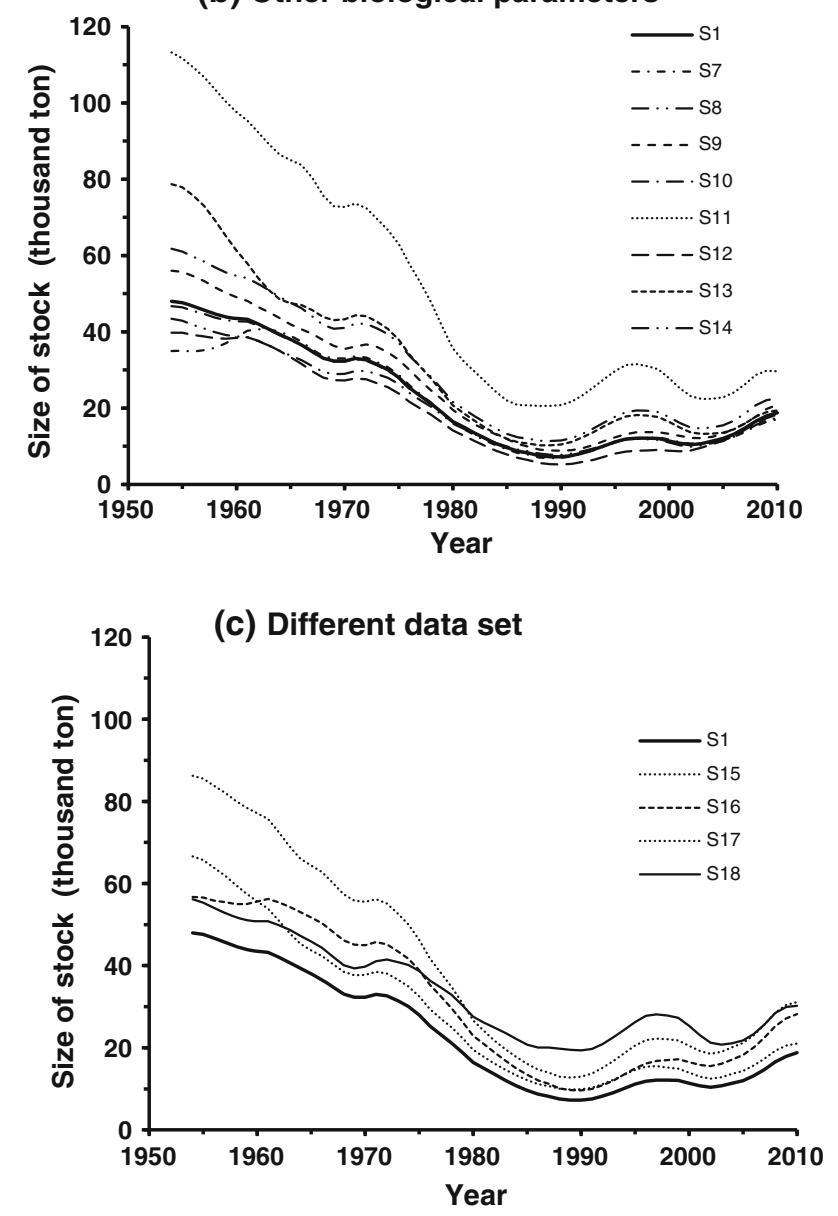

Fig. 9 Estimated trajectories of size of stock (1+ group) under each of the scenarios listed in Table 5

phenomena, one hypothesis is that the development reduced the survival rate of glass eels.

In the results of estimation, the exploitation rate for glass eels was considerably large, and attention should be drawn to the impact of taking glass eels on the mature components of the stock. By simply calculating the effect
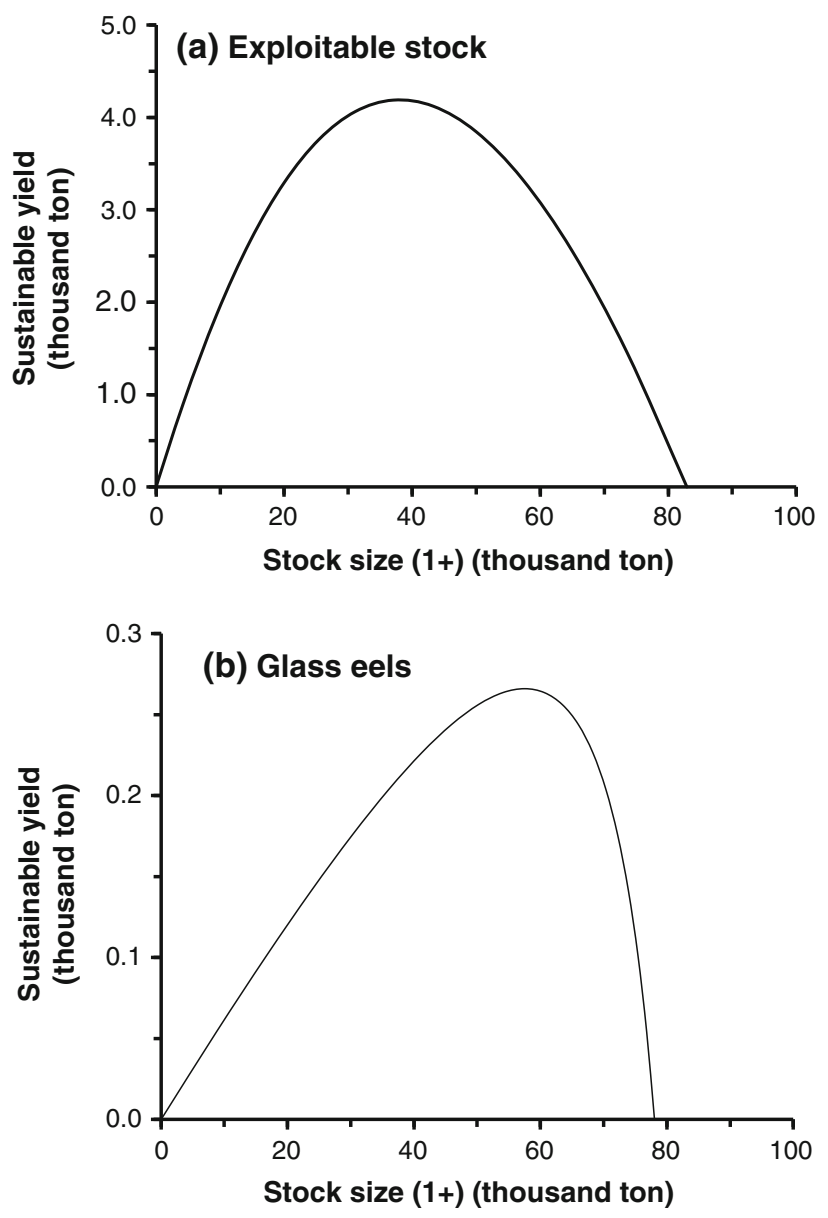

Fig. 10 Sustainable yield curves under the two extreme scenarios

of glass eels takes in terms of the mature component, the number of glass eels in a catch of $1 \mathrm{~kg}$ is about 6,700 individuals, which corresponds to about 50 mature females ( $38 \mathrm{~kg}$ in total), assuming that all females are sexually mature at age 9 and that natural mortality only occurs.

The MSY from glass eels will yield 228 thousand tons of aquaculture production, indicating the recent ratio of aquaculture landing to input of glass eels (857-fold for Japanese aquaculture), which is 55-fold the MSY from the exploitable stock. From the aspect of economic productivity, aquaculture has a relatively dominant position compared to the fisheries. On the other hand, economic productivity causes heavy overexploitation of the natural eel stock. Management objectives should be carefully decided upon by considering some tradeoffs.

Regulation of the catch for exploitable stock was recently considered in Japan as a means to allow the adult stock to recover. However, the regulation will not have a substantial effect on rehabilitation because the estimated exploitation rate has already decreased to a very small level, as shown in Table 7 and Fig. 7. 
Another measure of stock management is to regulate takes for glass eels. Some measures for minimizing the loss due to new regulations will be required since regulation of the takes may lead to greater economic loss of the aquaculture industry, and the current supply of artificial glass eels is inadequate. A practical measure for minimizing the loss is to rear and release that part of glass eels taken as seeds for aquaculture in order to ensure a certain annual number of juveniles. Let us suppose that the survival rate for glass eels in a given year is $80 \%$ in aquaculture and $3 \%$ in the natural environment. Then, if $3.75 \%$ of glass eel takes were used for stocking seeds, aquaculture of the glass eels will produce stocking seeds at an amount equal to that of natural juveniles that were lost during the takes. Thus, the effect of glass eel takes can be canceled out by using a part of the glass eels taken for stocking seeds. This measure is expected to preserve genetic diversity in the stocking seeds since the latter originate from naturally matured stock. However, the above calculation is made using the assumed value of $M_{0}$, and I shall attempt to precisely estimate the value of $M_{0}$ in future research.

Acknowledgments The author would like to thank Shigehide Iwata, Assistant Professor, Tokyo University of Marine Science and Technology, for technical comments, and the anonymous reviewers for their constructive and valuable comments.

Open Access This article is distributed under the terms of the Creative Commons Attribution License which permits any use, distribution, and reproduction in any medium, provided the original author(s) and the source are credited.

\section{References}

1. Aida K, Tsukamoto K, Yamauchi K (2004) Eel biology. Springer, Tokyo

2. Matsui I (1972) Science of eel. Kouseisha Kouseikaku, Tokyo (in Japanese)

3. Ohtsuka H (1996) History of Economic Development of Eel Aquaculture. Nourin Toukei Kyoukai, Tokyo (in Japanese with English summary)

4. Yamamoto S (1936) On glass eel in Lake Haman. Month Rep Shizuoka Pref Fish Exp Stat 28:15-27 (in Japanese)

5. Nakagawa M, Nonaka M (1976) Some knowledges on the catch of elver in Lake Hamana. J Shizuoka Pref Fish Exp Stat 10:77-82 (in Japanese with English abstract)

6. Di Y, Li W (1993) Study on Development Histories of Industries of Shrimp and Eel in Chinese Continent. Shui Chan Chu Ban She, Keelung (in Chinese)

7. Quo H (1994) Detail Observation of Eel Aquaculture. Shui Chan Chu Ban She, Keelung (in Chinese)

8. Tatsukawa K (2001) The present state of population dynamics studies on unagi, Anguilla japonica. Kaiyo To Seibutsu 133:108-114 1 (in Japanese with English abstract)

9. Tanaka E (2013) Research survey of Japanese eel stock. In: Japanese branch of EASEC (ed) Unadon No Mirai, Seidosha, Tokyo, pp 51-70 (in Japanese)
10. Nourinshou (1970) The 4th Fisheries Census. Nourinshou, Tokyo (in Japanese)

11. Nourinshou (1955) Annual report of catch statistics on fishery and aquaculture-1954. Nourin Toukei Kyoukai, Tokyo (in Japanese)

12. De Leo GA, Gatto M (1995) A size and age-structured model of the European eel (Anguilla Anguilla L.). Can J Fish Aquat Sci 52:1351-1367

13. Fenske KH, Wilberg MJ, Secor DH, Fabrizio MC (2011) An ageand sex-structured assessment model for American eels (Anguilla rostrata) in the Potomac River, Maryland. Can J Fish Aquat Sci 68:1024-1037

14. Methot RD (1990) Synthesis model: an adaptable framework for analysis of diverse stock assessment data. Int North Pac Fish Comm Bull 50:259-277

15. Quinn TJ II, Deriso RB (1999) Quantitative fish dynamics. Oxford University Press, New York

16. Hilborn R, Walters CJ (1992) Quantitative fisheries stock assessment. Chapman and Hall, London

17. Ishikawa S, Aoyama J, Tsukamoto K, Nishida M (2001) Population structure of the Japanese eel Anguilla japonica as examined by mitochondrial DNA sequencing. Fish Sci 67:246-253

18. Tsukamoto K (1990) Recruitment mechanism of the eel, Anguilla japonica, to the Japanese coast. J Fish Biol 36:659-671

19. Tzeng WN, Lin HR, Wang CH, Xu SN (2000) Differences in size and growth rates of male and female migrating Japanese eels in Pearl River, China. J Fish Biol 57:1245-1253

20. Kotake A, Arai T, Okamura A, Yamada Y, Utoh T, Oka HP, Miller MJ, Tsukamoto K (2007) Ecological aspects of the Japanese eel, Anguilla japonica, collected from coastal areas of Japan. Zool Sci 24(12):1213-1221

21. Anonymous (2004) Report of contract research for propagation of Japanese eel stock. Jap Fish Resour Cons Assoc, Tokyo (in Japanese)

22. Anonymous (2012) Report of the 2012 Atlantic bluefin tuna stock assessment session. Available at: http://www.iccat.int/Docu ments/Meetings/Docs/2012_BFT_ASSESS.pdf

23. Anonymous (2012) Report of Scientific committee. J Cetacean Res Manage 13[Suppl]:1-73

24. Tokeikyoku Noushoumushou (1915) Annual Fisheries Statistics. Noushoumushou, Tokyo (in Japanese)

25. Nourinshou (1960) Statistical table of catch series from 1912 to 1958. Nourin Toukei Kyoukai, Tokyo (in Japanese)

26. Nourinshou Ibaragi Stat Res Bra (1955) Annuals of agriculture, forestry and fishery in 1954: part of fishery. Nourinshou Ibaragi Stat Res Bra, Mito (in Japanese)

27. Mie Pref Fish Exp Stat (1978) Information on catch for glass eels. Youman Kenkyuu Kyogikai Youroku 7:16-27 (in Japanese)

28. Anonymous (1998) Results of research survey of catch for glass eels in 1996 financial year. Youman Kenkyuu Kyogikai Youroku 27: 9-16 (in Japanese)

29. Nakagawa M (1979) Experimental takes of glass eels and survey of catch. In: Rep Shizuoka Pref Fish Exp Stat Showa 53 Nendo, Yaizu, pp 301-303 (in Japanese)

30. Iinuma N, Yoshikawa M (2005) Survey due to experimental takes of glass eels. In: Rep Shizuoka Pref Fish Exp Stat Heisei 16 Nenod, Yaizu, pp 163-16 (in Japanese)

31. Yoshikawa M (2005) Results of catch for glass eels in 2004 financial year. Hamana 510:3-4 (in Japanese)

32. Matsuyama H (2010) Results of catch for glass eels in 2005 financial year. Hamana 530:3-4 (in Japanese)

33. Hino S (1979) On migration of glass eels in the coast of Tokushima Prefecture. In: Rep Tokushima Pref Fish Exp Stat 1977-1978. Tokushima Prefecture Fish Experimental Station, Tokushima, pp 234-238 (in Japanese) 
34. Anonymous (1987) Amount of stocked glass eels in 1987. Youman Circle 35:5-5 (in Japanese)

35. Nihira A (2006) Catch fluctuations of Japanese eels Anguilla japonica in the Tone river and Lake Kasumigaura. J Ibaragi Inl Wat Fish Exp Stat 40:55-68 (in Japanese with English abstract)

36. Minami M, Cody CEL, Gao W, Verdesoto MR (2007) Modeling shark bycatch: the zero-inflated negative binomial regression model with smoothing. Fish Res 84:210-221

37. De Urbina JO, Cortés BG, Cartelle AR, Mejuto J (2013) Application of zero-inflated models to the catch rates of white marlin (Teterapturus albidus) based on data from the Spanish surface longline fishery targeting swordfish in the Atlantic ocean. Collect Vol Sci Pap ICCAT 69(3):1195-1212

38. Bru N, Prouzet P, Lejeune M (2009) Daily and seasonal estimates of the recruitment and biomass of glass eels runs (Anguilla anguilla) and exploitation rates in the Adour open estuary (Southwestern France). Aquat Living Resour 22:509-523

39. Berg S, Jorgensen J (1994) Stocking experiments with 0+ eel (Anguilla anguilla) in Danish streams: post-stocking movements, densities and mortality. In: Cowx IG (ed) Rehabilitation of freshwater fisheries. Blackwell, Oxford, pp 314-332

40. Bisgaard J, Pedersen MI (1991) Mortality and growth of wild and introduced cultured eels (Anguilla anguilla (L.)) in a Danish stream, with special reference to a new tagging technique. Dana 9:57-69

41. Tesch FW (2003) The eel, 3rd edn. Blackwell, Oxford

42. Edwards AWF (1972) Likelihood. Cambridge University, London

43. Seber GAF (1982) The delta method. The estimation of animal abundance, 2nd edn. Charles Griffin, London, pp 7-9

44. Kotake A, Okamura A, Yamada Y, Utoh T, Arai T, Miller MJ, Oka HP, Tsukamoto K (2005) Seasonal variation in the migratory history of the Japanese eel Anguilla japonica in Mikawa Bay. Japan Mar Ecol Prog Ser 293:213-221

45. Kishida T, Kantou I (2012) Reconsideration of Japanese catch of glass eel. Fish Oceanogr 77(3):164-166 (in Japanese with English abstract)

46. Usui A (1976) Eel culture industry. In: Unagi. shibata Shoten, Tokyo, pp. 229-235 (in Japanese) 